\title{
HARGA DAN PHYSICAL EVIDENCE TERHADAP KEPUASAN PELANGGAN WARUNG UPNORMAL
}

\author{
Indah Purnama Sari $^{1)}$, Tiara Elsya Medyani $^{2)}$ \\ ${ }^{1,2}$ Program Studi Pendidikan Ekonomi, FIPPS \\ Universitas Indraprasta PGRI, Indonesia \\ Email : indahps.unindra@gmail.com ${ }^{1)}$; \\ tiaraelsya@gmail.com ${ }^{2)}$
}

Diterima: Juni 2018; Disetujui: Juli 2018; dipublikasikan: Agustus 2018

\begin{abstract}
ABSTRAK
Tujuan penelitian ini adalah untuk mengetahui pengaruh harga dan physical evidence terhadap kepuasan pelanggan, baik secara parsial maupun simultan. Sampel diambil sejumlah 100 orang secara acak dari pelanggan Warunk Upnormal. Data dikumpulkan menggunakan kuesioner. Data kemudian dianalisis dengan metode kuantitatif yaitu analisis regresi linier berganda. Berdasarkan hasil uji t, ditemukan bahwa variabel harga berpengaruh signifikan terhadap kepuasan pelanggan, demikian juga variabel physical evidence berpengaruh signifikan terhadap kepuasan pelanggan. Adapun hasil uji $\mathrm{F}$ menunjukkan kedua variabel bebas secara bersama-sama berpengaruh signifikan terhadap kepuasan pelanggan. Berdasarkan uji $\mathrm{R}^{2}$ menunjukkan kontribusi variabel harga dan physical evidence, cukup besar pada variabel kepuasan pelanggan. Rekomendasi bagi perusahaan yaitu, menentukan harga yang tepat sesuai target pasar serta melengkapi fasilitas dengan fasilitas yang unik, kreatif, dan memiliki diferensiasi dengan usaha sejenis. Untuk usaha restoran, faktor physical evidence akan mempengaruhi keputusan pelanggan untuk mengulangi kunjungan. Jika pelanggan merasa puas, maka besar kemungkinan mereka akan menjadi pelanggan yang loyal.
\end{abstract}

Kata kunci: harga, physical evidence, kepuasan pelanggan

\begin{abstract}
The purpose of this study is to determine the effect of price and physical evidence on customer satisfaction, either partially or simultaneously. Samples were taken in 100 randomly from the Warunk Upnormal customers. Data were collected using questionnaires. Data then analyzed by quantitative method that is multiple linear regression analysis. Based on the result of t test, it is found that the price variable has a significant effect on customer satisfaction, and also the physical evidence variable has a significant effect on customer satisfaction. The results of the F test shows the two independent variables together have a significant effect on customer satisfaction. Based on $R 2$ test shows the contribution of price variable and physical evidence, big enough on customer satisfaction variable. Recommendations for companies that is, determine the right price according to the target market as well as equip facilities with unique facilities, creative, and have differentiation with similar businesses. For restaurant businesses, physical evidence factors will affect the customer's decision to repeat the visit. If customers feel satisfied, then most likely they will become loyal customers.
\end{abstract}

Keywords: price, physical evidence, customer satisfaction 


\section{PENDAHULUAN}

Era persaingan bisnis yang sangat tajam saat ini, membuat setiap perusahaan yang ingin memenangkan persaingan harus berpikir dari sudut pandang upaya dalam rangka memberikan kepuasan kepada para pelanggannya. Kepuasan pelanggan menjadi suatu indikator penting yang menentukan kesuksesan perusahaan karena jika pelanggan merasa tidak dipuaskan, maka mereka akan meninggalkan perusahaan dan menjadi pelanggan pihak pesaing. Hal ini akan mengakibatkan penjualan perusahaan akan menurun sehingga pada akhirnya laba penjualan juga akan menurun. Oleh karena itu, perusahaan perlu melakukan upaya-upaya sistematis untuk bisa mengontrol kepuasan pelanggan. Bila diketahui pelanggan tidak puas, perlu segera dianalisis faktor-faktor penyebabnya untuk selanjutnya dilakukan evaluasi dan perbaikan.

Ada banyak aspek yang dapat mempengaruhi kepuasan pelanggan, utamanya jenis usaha yang bergerak di bidang jasa, misalnya aspek produk atau jasa itu sendiri, aspek pelayanan terhadap konsumen, aspek harga, aspek tempat, aspek fasilitas untuk pelanggan, dan sebagainya.

Warunk Upnormal adalah salah satu warung kekinian yang digemari oleh banyak kalangan utamanya kalangan remaja. Warunk Upnormal didirikan oleh Citarasa Prima Group (CRP Group) sejak Juni 2014 dan kini sudah memiliki banyak cabang di berbagai kota besar.

Warunk Upnormal sejak awal berdiri menawarkan konsep produk yang unik, yaitu menawarkan berbagai kreasi mie instan. Warunk Upnormal menggunakan tagline "pelopor mie kekinian", sesuai dengan produk andalannya yaitu berbagai macam kreasi mie instan yang sangat unik.

Seiring dalam perkembangan zaman Warunk Upnormal terus berinovasi salah satunya mengembangkan menu. Pada akhirnya Warunk Upnormal memiliki menu-menu tambahan seperti susu, kopi, roti, dessert, dan aneka nasi.

Produk yang ditawarkan Warunk Upnormal memiliki kisaran harga yang cukup terjangkau, ditunjang dengan aspek tempatnya dan fasilitas yang unik. Layout untuk setiap outlet distandarkan sesuai dengan perjanjian yang telah diatur oleh kantor pusat. Salah satu ketentuan outlet adalah memiliki luas bangunan kurang lebih $400 \mathrm{~m}^{2}$, dengan lebar minimal 8 meter. Meja dan kursi disuplai langsung oleh pusat dengan ukuran dan desain yang telah distandarkan pula. Selain itu dapur harus terpisah, tersedia toilet, tempat ibadah, berbagai permainan, stop kontak tersedia disetiap sudut dan bawah sofa, wifi yang dapat diakses oleh setiap pengunjung.

Pelanggan yang masuk ke Warunk Upnormal akan dimanjakan oleh desain interior yang unik. Hiasan-hiasan yang ada pada dinding memiliki warna yang cerah dan vintage. Warunk Upnormal juga menyediakan ruangan khusus atau biasa disebut private room yang dapat dipesan untuk acara tertentu seperti meeting, ulang tahun ataupun acara reuni, dan acara eksklusif lainnya. Di dalam private room tersedia fasilitas seperti infocus, speaker dan mic.

Dari deskripsi di atas tampak bahwa Warunk Upnormal sangat memperhatikan kebutuhan pelanggan, mengupayakan sesuatu yang memuaskan bagi setiap pengunjung sehingga pengunjung ini menjadi pelanggan yang loyal. Dengan harga yang relatif terjangkau dan berbaga fasilitas yang ada, tentu saja Warunk Upnormal berharap bisa memuaskan pelanggannya. Fenomena ini menarik untuk dikaji apakah harga dan physical evidence berpengaruh terhadap kepuasan pelanggan, khususnya bagi obyek penelitian Warunk Upnormal.

\section{Kepuasan Pelanggan}

Kotler dan Clarke mendefinisikan kepuasan sebagai pernyataan perasan dari seseorang yang telah memperoleh kinerja layanan atau hasil untuk pemenuhan terhadap harapannya. Kepuasan merupakan fungsi dari tingkat relatif dari apa yang diharapkan dan kenyataan apa yang diterima (Algifari, 2016). 
Kepuasan pelanggan merupakan sesuatu yang dapat diukur dan dapat diketahui dengan cara yang cukup mudah, seperti : perusahaan menyediakan formulir keluhan dan saran, melakukan survey kepuasan pelanggan, melibatkan konsumen bayangan, serta melakukan analisis konsumen yang beralih kepada perusahaan yang lain.

Banyak hal yang dapat dilakukan oleh perusahaan dalam rangka memberikan kepuasan kepada pelanggan, seperti memberikan produk yang mutunya lebih baik, harganya lebih murah, penyerahan produk yang lebih cepat, dan pelayanan yang lebih baik daripada pesaingnya (Supranto, 2011).

\section{Harga}

Faktor harga adalah salah satu faktor yang menentukan bagi konsumen Indonesia yang sangat sensitif terhadap harga. Mayoritas masyarakat Indonesia hidup dalam skala perekonomian menengah ke bawah, menentukan keputusan pembelian dengan menjadikan harga sebagai pertimbangan utama.

Harga merupakan satu-satunya elemen dari bauran pemasaran yang menghasilkan pendapatan (Sumarwan \& dkk, 2009). Selain itu, harga memiliki pengaruh yang signifikan terhadap keberhasilan perusahaan karena keuntungan dari tiap unit yang terjual akan mempengaruhi keuntungan perusahaan. Hal lain seputar harga adalah, harga dapat mempengaruhi persepsi konsumen. Jika harga yang ditetapkan rendah, bisa jadi konsumen menganggap barang tersebut berkualitas rendah, demikian sebaliknya. Dengan demikian, perusahaan perlu melakukan sejumlah strategi dalam menetapkan harga optimal. Harga optimal adalah harga yang paling menguntungkan bagi perusahaan, didapatkan dengan caramencari harga terbaik yang bisa memberi kontribusi terbesar setelah dikurangi variabel costnya (Sumarwan \& dkk, 2009).

Lebih lanjut Sumarwan, dkk (2009) mengatakan bahwa harga merupakan bagian penting nilai pelanggan dan profitabilitas usaha. Harga tinggi memang baik untuk margin namun hal ini dapat menimbulkan menurunnya volume pelanggan. Pendekatan terbaik untuk menghasilkan harga terbaik dalam pasar kompetitif adalah melalui pendekatan market based pricing yang dimulai dengan kebutuhan pelanggan, posisi pesaing, dan penempatan produk usaha, serta bekerja mundur ke margin (Sumarwan \& dkk, 2009).

Pendapat senada disampaikan oleh Basrowi (2011). Menurut Basrowi, untuk mencapai keunggulan bersaing, seorang pengusaha harus mampu meningkatkan daya inovasi, kreatif, dan produktivitas dengan teknik-teknik yang dimiliki, sehingga dapat bersaing baik secara produk maupun harga (Basrowi, 2011). Dalam hal ini pengusaha dituntut mampu menghasilkan produk dengan biaya yang relatif rendah, sehingga bisa menetapkan harga yang bisa bersaing. Hal ini karena terdapat kelompok pelanggan yang sensitif terhadap harga, dimana selisih Rp. 1000 saja dengan produk pesaing maka kelompok pelanggan ini akan mempertimbangkan kembali apakah akan tetap setia atau justru akan pindah pada produk yang lain (pesaing).

Kendati aspek harga sangat penting, tidak dapat berdiri sendiri tanpa disokong oleh kemampuan bersaing pada aspek lain. Perusahaan perlu berpikir untuk menyenangkan konsumen. Menyenangkan ini bisa dari berbagai aspek, seperti kualitas produk yang bermutu, memberi kepuasan, sangat memperhatikan pengalaman konsumen, serta keistimewaan layanan yang unik.

Berkaitan dengan layanan yang unik, perusahaan dapat memaksimalkan variabel physical evidence.

\section{Physical Evidence}

Physical evidence merupakan salah satu dari 7P dalam bauran pemasaran. Menurut Tjiptono (2008) dalam (Sari \& Oetomo, 2013), physical evidence merupakan bukti fisik dari jasa yang ditawarkan. Physical evidence (fasilitas pendukung) merupakan bagian dari pemasaran jasa yang memiliki peranan cukup penting (Sari, Ikaningtyas, \& Desnaranti, 2018). 
Sebagai perusahaan yang bergerak di bidang jasa, maka setiap usaha restoran perlu memperhatikan unsur ini.

Hal senada juga disampaikan oleh Nirwana (2004) dalam (Nugroho \& Japarianto, 2013) bahwa "fasilitas pendukung merupakan bagian dari pemasaran jasa yang memiliki peranan cukup penting. Karena jasa yang disampaikan kepada pelanggan tidak jarang memerlukan fasilitas pendukung di dalam penyampaian". Fasilitas pendukung ini biasanya berwujud dalam layanan fisik. Dalam rangka menciptakan layanan yang berkualitas perusahaan perlu memperhatikan elemen layanan fisik ini, diantaranya adalah prasarana gedung, fisik gedung, fasilitas pendingin, alat telekomunikasi, perabot yang berkualitas, ruang toilet yang bersih, dan sebagainya.

Ada 3 cara dalam mengelola bukti fisik yang strategis yaitu (Nugroho \& Japarianto, 2013): 1) An attention-creating medium. Perusahaan jasa melakukan diferensiasi dengan pesaing dan membuat sarana fisik semenarik mungkin untuk menjaring pelanggan dari target pasarnya. 2) As a massage-creating medium. Menggunakan simbol atau isarat untuk mengkomunikasikan secara instensif kepada audiens mengenai kekhususan kualitas dan produk atau jasanya. 3) An effect-creating medium. Baju seragam yang berwarna, bercorak, suara dan desain untuk menciptakan sesuatu yang lain dari produk atau jasa yang ditawarkan.

Berdasarkan beberapa pendapat para ahli yang didukung oleh hasil penelitian empiris (Diasari \& Oetomo, 2016), (Ghozali, 2014), (Sari \& Oetomo, 2013), dan (Jacobus \& Wahyudi, 2017), maka kajian ini ingin menguji kebenaran beberapa hipotesis sebagai berikut :

H1 : Harga berpengaruh signifikan dan positif terhadap kepuasan pelanggan

$\mathrm{H} 2$ : Physical evidence berpengaruh signifikan dan positif terhadap kepuasan pelanggan

H3 : Harga dan physical evidence secara bersama-sama signifikan dan positif terhadap kepuasan pelanggan.

\section{METODE}

Metode yang digunakan dalam penelitian ini adalah metode kuantitatif. Berdasarkan tingkat eksplanasi, penelitian ini termasuk penelitian asosiatif. Variabel yang digunakan dalam penelitian ini adalah harga (variabel $\mathrm{X}_{1}$ ), physical evidence (variabel $\mathrm{X}_{2}$ ), dan kepuasan pelanggan (variabel Y).

Populasi dalam penelitian ini adalah semua konsumen Restoran "X". Jumlah sampel sebanyak 100 responden diambil dengan teknik simple random sampling. Jumlah 100 dipandang mewakili untuk jumlah populasi tak terhingga.

Metode pengumpulan data yang digunakan dalam penelitian ini adalah metode kuesioner dan metode dokumentasi. Dalam penyebaran kuesioner peneliti melakukan kontak langsung dengan responden sehingga diharapkan responden dengan sukarela akan memberikan data yang obyektif dan cepat, mengisi kuesioner dengan jawaban yang sesungguhnya, serta untuk memastikan kuesioner kembali kepada peneliti dan meminimalkan ketidak kembalian kuesioner. Studi dokumentasi juga dilakukan dalam penelitian ini dengan pelakukan pengkajian terhadap sejumlah literatur atau kajian empiris yang relevan dengan tema penelitian.

Instrumen pengumpulan data yang digunakan adalah kuesioner. Kuesioner disusun berdasarkan indikator dari tiap variabel penelitian. Adapun skala pengukuran terhadap instrument menggunakan skala likert dengan rentang skor mulai dari 1 sampai dengan 5. Skala likert dalam penelitian ini termasuk ke dalam skala ordinal. Untuk mengukur variabel harga, menggunakan indikator : harga produk, kualitas produk, daya beli produk, perbandingan harga dengan tempat lain, kemampuan harga bersaing dengan tempat lain. Untuk mengukur variabel physical evidence menggunakan indikator: kondisi ruangan, pengaturan cahaya, sarana pengatur suhu ruangan, dekorasi interior, fasilitas stop kontak, tersedia games, tersedia sound system, fasilitas toilet, fasilitas sarana ibadah, tersedia lahan parkir. Adapun untuk mengukur variabel 
kepuasan pelanggan menggunakan indikator: puas dengan harga, puas dengan fasilitas, sesuai dengan kenyataan, akan datang kembali ke tempat tersebut, merekomendasikan tempat.

Teknik analisis data yang digunakan adalah analisis data kuantitatif deskriptif dengan menggunakan alat bantu SPSS 23.0 for windows. Teknik analisis data meliputi: analisis regresi linier berganda dan uji goodness of fit model regresi meliputi uji t, uji $F$ dan uji $R^{2}$. Uji $t$ digunakan untuk menguji signifikansi pengaruh harga terhadap kepuasan pelanggan, dan untuk menguji signifikansi pengaruh physical evidence terhadap kepuasan pelanggan. Uji F digunakan untuk menguji signifikansi variabel harga dan physical evidence terhadap motivasi kepuasan pelanggan.

\section{HASIL DAN PEMBAHASAN}

Model regresi yang diperoleh berdasarkan hasil penelitian dapat dituliskan dalam bentuk persamaan regresi sebagai berikut:

$\mathrm{Y}=4,358+0,498 \mathrm{X}_{1}+0,139 \mathrm{X}_{2}$. Dari persamaan tersebut, variabel $\mathrm{X}_{1}$ memiliki koefisien regresi dengan arah positif, demikian juga dengan variabel $\mathrm{X}_{2}$ memiliki koefisien regresi dengan arah positif. Hal ini menunjukkan bahwa semakin baik penetapan harga dan semakin baik pengelolaan physical evidence, akan meningkatkan kepuasan pelanggan.

Adapun uji goodness of fit model regresi dilakukan dengan menguji nilai statistik $\mathrm{t}$, nilai statistik F, dan koefisien determinasi (R2) pada hasil regresi yang telah memenuhi uji asumsi klasik, didapatkan hasil sebagai berikut:

Berdasarkan perhitungan regresi dengan bantuan SPSS diketahui bahwa determinasi (adjusted $\mathrm{R}^{2}$ ) yang diperoleh sebesar 0,394. Hal ini menunjukkan 39,4\% variabel terikat kepuasan pelanggan dapat dijelaskan oleh variabel bebas yaitu harga dan physical evidence. Dengan demikian hal ini juga menunjukkan bahwa motivasi wirausaha dapat dijelaskan oleh variabel lainnya sebesar $60,6 \%$.

Lebih lanjut hasil uji t menunjukkan semua variabel bebas memiliki pengaruh signifikan. Uji parsial menunjukkan variabel harga memiliki t hitung sebesar 6,873 lebih besar daripada $t$ table 1,984 dengan signifikansi sebesar 0,000 lebih kecil dari 0,05 hal ini menunjukkan pengaruh harga dalam kepuasan pelanggan signifikan. Adapun variable physical evidence memiliki t hitung sebesar 3,592 lebih besar dari t tabel 1,984 dengan signifikansi 0,001 lebih kecil dari 0,05 menunjukkan variabel physical evidence pengaruhnya signifikan terhadap kepuasan pelanggan.

Hasil uji $\mathrm{F}$ berdasarkan hasil uji ANOVA didapatkan nilai $\mathrm{F}$ hitung 33,135 lebih besar dari $\mathrm{F}$ tabel 3,09 dan signifikansi sebesar 0,000 lebih kecil dari 0,05 menunjukkan variabel kepuasan pelanggan dapat dijelaskan oleh variabel harga dan physical evidence secara bersamasama atau dengan kata lain semua variabel bebas secara bersama-sama merupakan penjelas yang signifikan terhadap variabel terikat.

Hasil pengolahan data untuk menguji hipotesis disajikan pada Gambar 1 sebagai berikut:

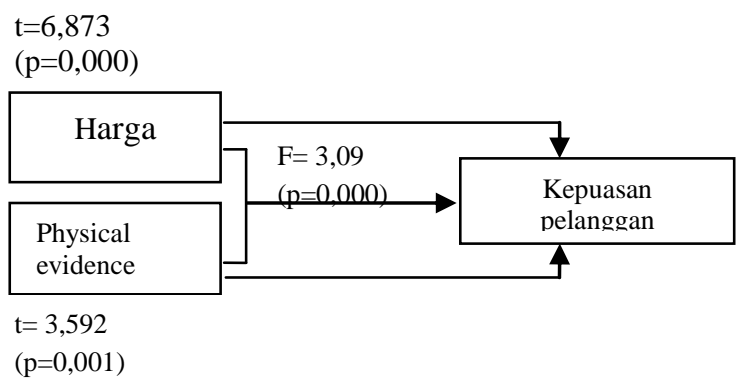

Gambar 1. Hasil Pengujian Hipotesis 
Berdasarkan hasil pengujian hipotesis disimpulkan bahwa semua hipotesis yang diajukan, diterima, di dalam penelitian ini telah terbukti kebenarannya. Variabel harga dan physical evidence terbukti signifikan baik secara parsial maupun secara bersama-sama mempengaruhi kepuasan pelanggan. Dengan kata lain, hasil penelitian ini menunjukkan bahwa penentuan harga yang tepat dan pengelolaan physical evidence yang baik akan mampu meningkatkan kepuasan pelanggan. Dengan demikian, hasil penelitian ini semakin menguatkan hasil penelitian sebelumnya.

\section{SIMPULAN}

Simpulan dari penelitian ini adalah: harga berpengaruh signifikan dan positif terhadap kepuasan pelanggan, physical evidence berpengaruh signifikan dan positif terhadap kepuasan pelanggan. Adapun kedua variable bebas secara bersama-sama berpengaruh siginifikan dan positif terhadap kepuasan pelanggan.

Rekomendasi bagi perusahaan untuk dapat meningkatkan kepuasan pelanggan yaitu, menentukan harga yang tepat sesuai dengan target pasar yang dituju, dan akan lebih baik jika menjadi pemimpin harga dalam pasar produk sejenis. Karena pelanggan sangat sensitif dalam memaknai harga, maka perusahaan perlu menguatkan harga dari segi yang lain, seperti melengkapi fasilitas dan memberikan fasilitas yang unik, kreatif, dan memiliki diferensiasi dengan usaha sejenis. Untuk jenis usaha restoran, faktor physical evidence akan sangat mempengaruhi keputusan pelanggan untuk mengulangi kunjungan. Jika pelanggan merasa puas, maka besar kemungkinan mereka akan menjadi pelanggan yang loyal.

\section{DAFTAR RUJUKAN}

Algifari. (2016). Mengukur Kualitas Layanan dengan Indeks Kepuasan, Metode ImportancePerformance Analysis (IPA) dan Model Kano. Yogyakarta: BPFE.

Basrowi. (2011). Kewirausahaan untuk Perguruan TInggi. Bogor: Ghalia Indonesia.

Diasari, S. A., \& Oetomo, H. W. (2016). Pengaruh Harga, Produk dan Kualitas Pelayanan terhadap Kepuasan dan Loyalitas Pelanggan. Jurnal Ilmu dan Riset Manajemen Vol 5 No 12 Desember, 1-20.

Ghozali, M. (2014). Pengaruh Kualitas Pelayanan dan Harga terhadap Kepuasan Pelanggan pada Expedisi di Surabaya. Jurnal Ilmu dan Riset Manajemen Vol 3 No 3, 1-15.

Jacobus, V., \& Wahyudi, T. A. (2017). Pengaruh Physical Evidence, Harga, dan Produk terhadap Kepuasan serta Dampaknya terhadap Loyalitas Pelanggan Hypermarket. NCBM 2017 Kalbis Institute (pp. 1-15). Jakarta: Kalbis Institute.

Nugroho, R., \& Japarianto, E. (2013). Pengaruh People, Physical Evidence, Product, Promotion, Place, dan Place terhadap Tingkat Kunjungan di Cave Coffee Cozies Surabaya. Jurnal manajemen Pemasaran Petra Vo 1 No 2 , 1-9.

Sari, I. P., Ikaningtyas, S., \& Desnaranti, L. (2018). Peningkatan Mutu Physical Evidence di Sekolah Dasar melalui Gerakan Toilet Ramah Anak. Jurnal PKM : Pengabdian kepada Masyarakat Vol 01 No 02 Mei-Agustus, 128-135.

Sari, M., \& Oetomo, H. W. (2013). Pengaruh Physical Evidence terhadap Kepuasan Pelanggan Lottemart dengan Aksesibilitas sebagai Variabel Moderator. Jurnal Ilmu dan Riset Manajemen Vol 4 No 10 Oktober, 1-15.

Sumarwan, U., \& dkk. (2009). Pemasaran Strategik, Strategi untuk Pertumbuhan Perusahaan dalam Penciptaan Nilai bagi Pemegang Saham. Jakarta: Inti Prima.

Supranto. (2011). Pengukuran Tingkat Kepuasan Pelanggan. Jakarta: Rineka Cipta. 


\section{Sosio e-kons}

Volume 10, No. 2, Agustus 2018, pp. 115-120

e-ISSN: 2502-5449

p-ISSN: 2085-2266

http://journal.lppmunindra.ac.id/index.php/sosio_ekons 